Disclosure of Interest: None declared DOI: 10.1136/annrheumdis-2018-eular.6290

\section{AB1274 HEALTH RECORD AIMING TO PROMOTE PATIENT PARTICIPATION IN RHEUMATOID ARTHRITIS PATIENTS ON THE USE OF DISEASE-MODIFYING ANTIRHEUMATIC DRUGS AND OUTCOME IN DAILY CLINICAL PRACTICE}

W.D. Müskens ${ }^{1}$, S.A.A. Rongen-van Dartel ${ }^{1,2}$, E. Adang ${ }^{3}$, P.L. van Riel ${ }^{1,2}{ }^{1} / Q$ Healthcare, Radboud UMC, Nijmegen; ${ }^{2}$ Rheumatology, Bernhoven, Uden; ${ }^{3}$ Health Evidence, Radboud UMC, Nijmegen, Netherlands

Background: Current guidelines say that there should be a prominent place for patient participation and shared decision making in rheumatic care.

To achieve this Bernhoven introduced an online patient health record (OPHR) for patients with rheumatoid arthritis (RA) aiming to facilitate self management and giving insight in the individual disease course in April 2014. This platform enables patients to monitor their disease by completing questionnaires about for instance pain, fatigue and quality of life. It also gives access to their medication history and offers patients information in the form of an online library.

Objectives: This study analyses how the introduction of an OPHR, aiming to promote patient participation, influences the prescription of DMARD's and the disease activity (DAS28) in daily clinical practice. A distinction was made between the effects of the PHR on patients recently diagnosed with RA (study A) and the RA population as a whole (study B).

Methods: In April 2014 anan OPHR for patients with RA was introduced at the rheumatology department of Bernhoven.

Using data from the rheumatology department registry, two analyses were performed to evalute this implementation.

Study A compared the treatment and course of DAS28 of patients diagnosed in the period three years prior to the implementation ("prior group") with those diagnosed in the period three years after the implementation ("after group").

Study B was an observational study that examined yearly trends for DMARD use and DAS28 for the whole RA population between April 2011 and April 2017

Results: Study A

A total of 287 patients were diagnosed with RA of which 127 were in the prior group and 171 in the after group. CsDMARD's were given 160 days [95\%>Cl 123-198] after diagnosis in the "prior group" versus (vs.) 32 days [ $95 \%>\mathrm{Cl} 22-43]$ in the after group. Next to that there was an increase in cumulative time csDMARD's were used during follow-up, $54 \%$ vs. $74 \%$ (p-value $<0.001$ ). Also, more patients received csDMARD combination therapy, $49 \%$ vs. $64 \%$ (pvalue $=0.001)$. There was no difference in number of patients that started a bDMARD, $7 \%$ vs. $14 \%$ ( $p$-value=0.059). However, a significant larger group started with a bDMARD in the first year after start of csDMARD therapy in the after group, $3.1 \%$ vs. $9.9 \%$ (p-value 0.024 ). $39 \%$ of the prior group vs. $69 \%$ in the after group achieved either remission or LDA within the first year of DMARD therapy ( $p$ value $<0.001)$.

Study B

The trend analysis of DMARD use in the RA population is plotted in figure 1 . Between 2011 and 2017 a change in trend can be observed for the use of csDMARD's, the use of cSDMARD combination and the use of bDMARD csDMARD combination therapy. The usage of bDMARD therapy did not change.

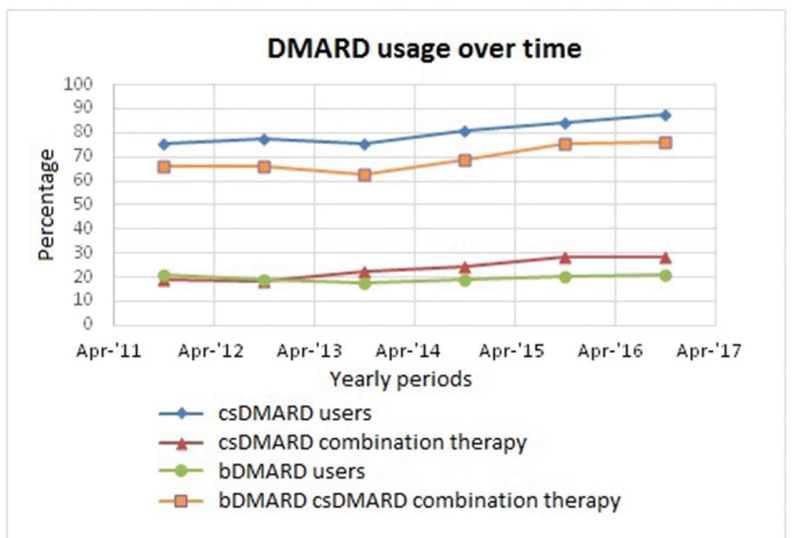

Abstract AB1274 - Figure 1. Trends in DMARD prescription, per yearly period
Conclusions: After the introduction of the OPHR patients recently diagnosed with RA got earlier and more intense treatment, with a more prominent role for biologicals. Next to that a bigger proportion of patients recently diagnosed with RA achieved remission and LDA within the first year of DMARD therapy. When looking for trends in the total RA population, an increase of the use of csDMARD's, the use of csDMARD combination and the use of bDMARD csDMARD combination therapy was observed after April 2014.

Disclosure of Interest: None declared

DOI: 10.1136/annrheumdis-2018-eular.2401

\section{AB1275 RESEARCH CONTRIBUTION TO THE JOURNAL OF ANNALS OF THE RHEUMATIC DISEASES FROM 2012 TO 2016: A BIBLIOMETRIC ANALYSIS}

Y. Tetik-Aydogdu', O. Aydogdu' ${ }^{2}$ Z. Sarı ${ }^{2} .{ }^{1}$ Physiotherapy and Rehabilitation, Haydarpassa Numune Education and Research Hospital, Department of Physiotherapy and Rehabilitation; ${ }^{2}$ Physiotherapy and Rehabilitation, Marmara University, Faculty of Health Sciences, Department of Physiotherapy and Rehabilitation, Istanbul, Turkey

Background: Rheumatology, a subspecialty of medicine, is devoted to diagnosis and therapy of rheumatic diseases, including clinical problems in joints, soft tissues, and autoimmune diseases. "Annals of the Rheumatic Diseases" is one of the most read and prestigious journals in the field of rheumatology. Bibliometric studies concerning the quantity and quality of articles published in rheumatology journals are scarce. The scientific production in the field of rheumatology from 1996 to 2010 was compared by Cheng. ${ }^{1}$ On the other hand, as to our knowledge, there is no study investigating research contribution to Annals of the Rheumatic Diseases since 2012.

Objectives: This study aims to investigate countries' research contribution in the field of rheumatology by classifying scientific papers according to their countries between 2012 and 2016 in Annals of the Rheumatic Diseases, official journal of EULAR.

Methods: All scientific papers which were published from 2012 to 2016 in Annals of the Rheumatic Diseases were screened. Some scientific papers such as editorial, viewpoint notes, or letters were excluded. In addition, supplementary issues were excluded as well. Rest of the papers were separated in two different part: "clinical and epidemiological research" and "basic and translational research". The papers were investigated one-by-one to determine their countries. All papers were classified according to their corresponding author.

Results: A total of 1616 scientific papers were investigated. Totally 1092 papers were included. While clinical and epidemiological research included 753 articles, basic and translational research contained 339 articles. There are 211, 188, 260 235,198 published articles in 2012, 2013, 2014, 2015, 2016, respectively. , In 2012 2014 and 2015 the top countries to publish articles in Annals of the Rheumatic Diseases are England, Netherlands and USA. In 2013 and 2016, France is in the list of top countries instead of Netherlands. While, 46,37 and 37 articles were published from England, Netherlands and USA, respectively in 2012, 53, 35 and 18 articles were published from England, USA and France, respectively in 2016.

Conclusions: According to our results, Western Europe and USA clearly dominate the production of scientific papers in Annals of the Rheumatic Diseases, official journal of EULAR. Our results are in accordance with the literature. We conclude that research resources, financial and other some issues may contribute the publishing process.

\section{REFERENCE:}

[1] Cheng T, Zhang G. Worldwide research productivity in the field of rheumatology from 1996 to 2010: a bibliometric analysis. Rheumatology (Oxford). 2013 Sep;52(9):1630-4.

Disclosure of Interest: None declared DOI: 10.1136/annrheumdis-2018-eular.6856

\section{AB1276 ECONOMIC IMPACT OF NON-MEDICAL SWITCHING FROM ORIGINATOR BIOLOGICS TO BIOSIMILARS - A SYSTEMATIC LITERATURE REVIEW}

Y. Liu ${ }^{1}$, V. Garg ${ }^{2}$, M. Yang ${ }^{3}$, E.Q. Wu ${ }^{3}$, M. Skup ${ }^{2} .{ }^{1}$ Division of Pharmacy Practice and Administration, The University of Missouri, Kansas City, ${ }^{2}$ AbbVie, Chicago; ${ }^{3}$ Analysis Group, Inc., Boston, USA

Background: Biosimilars, often priced at a discounted rate of originator biologics, may prompt switching patients from originator biologics to biosimilars for nonmedical reasons. However, other relevant costs (e.g., non-medical switching (NMS) program setup, costs of concomitant therapies, additional healthcare resource utilisation [HRU]) associated with NMS are not well understood. 
Objectives: A systematic literature review (SLR) was conducted to review and summarise economic consequences of NMS from a biologic originator to its biosimilar.

Methods: English publications reporting HRU or costs associated with biosimilar NMS were searched in PubMed and Embase over the past 10 years, and from selected scientific conferences over the past 3 years, along with grey literature (e. g., organisational reports). Search strings for keywords (e.g. biosimilar, HRU, cost, switch etc.) were combined using Boolean operators for all relevant agents with an approved biosimilar (e.g., tumor-necrosis factor inhibitors, erythropoiesisstimulating agents, insulin, hormone therapies).

Results: A total of 244 publications were retrieved for review, where 122 were identified from the database search, 117 from conference abstracts and 5 from grey literature. Of these publications, 23 reported costs or HRU associated with biosimilar NMS, including 10 center-based cohort studies (all except one were single arm), 10 budget impact models/simulation studies, 2 national registry studies, and 1 policy review. Only three studies reported real-world HRU: a single-centre, two-cohort study found that switching to biosimilars was associated with higher inpatient readmission rate $(80 \%$ vs $5 \%, \mathrm{p}<0.001)$, surgery rate $(29 \%$ vs. $0 \%$, $\mathrm{p}=0.02)$, and steroid use ( $60 \%$ vs. $8 \%, p<0.001)$; a single-centre, single-arm study reported extra visit/phone consultation with a provider among patients experiencing injection-site pain; a national registry-based study found that comparing 6 months before vs. after NMS, post-NMS had increased outpatient visit days (5.7 vs $5.4, p<0.001)$ and increased rates in $6 / 16$ service categories. Among the other 20 studies, most of them focused on potential cost savings with approximately half considering drug cost only. Estimation/simulation in cost savings varied substantially due to heterogeneity in study design and assumptions (e.g. disease areas, drug price discount rates, cost components, population size, study period etc.). Among these, discontinuing/switching or switching back to the originator was reported in four studies (rate range: $6 \%-29 \%$ ) and biosimilar dosing increase $(35 \%)$ was reported in one study. A policy review study pointed out that biologic rebates (commonly at $50 \%$ ) should be taken into account in the context of NMS.

Conclusions: Few real-world studies reported economic consequences of biosimilar NMS and found increased HRU in patients with biosimilar NMS. Studies of cost estimation have been largely limited to drug prices. Comprehensive evaluation on the economic impact of NMS should incorporate all important elements of economic outcomes such as drug price, biologic rebates, HRU, NMS program setup, administration, and monitoring costs.

Acknowledgements: Medical writing support was provided by Jessie Wang of Analysis Group; this support was funded by AbbVie.

Disclosure of Interest: Y. Liu Consultant for: AbbVie, V. Garg Shareholder of: AbbVie, Employee of: AbbVie, M. Yang Employee of: Analysis Group, Inc., which has received consultancy fees from AbbVie, E. Wu Employee of: Analysis Group, Inc., which has received consultancy fees from AbbVie, M. Skup Shareholder of: AbbVie, Employee of: AbbVie

DOI: 10.1136/annrheumdis-2018-eular.4975

\section{AB1277 1 VACCINATION STATUS AND KNOWLEDGE AND ATTITUDE ON VACCINE AMONG PATIENTS WITH RHEUMATIC DISEASE IN CHINA}

\author{
Y. Jiang ${ }^{1}$, X. Li ${ }^{2}$, X. Zhang ${ }^{1}$, Q. Lv¹, Y. Zhang ${ }^{1}$, J. Qi ${ }^{1}$, Z. Liao ${ }^{1}$, J. Gu ${ }^{1}$. \\ ${ }^{1}$ Rheumatology, The Third Affiliated Hospital of Sun Yat-Sen University, \\ Guangzhou; ${ }^{2}$ Rheumatology, The People's Hospital of Liuzhou City, Liuzhou, \\ China
}

Background: Rheumatic diseases are associated with an increased susceptibility to infections. ${ }^{1}$ Specific inactivated vaccinations are recommended for patients with autoimmune diseases. ${ }^{2-4}$ However, vaccination coverage among patients with rheumatic disease is extremely low in China.

Objectives: Our study was to discover infection and vaccination status in patients with rheumatic diseases in recent five years. and then to determine knowledge and attitude on vaccine among patients with rheumatic diseases.

Methods: A questionnaire-based survey was conducted in a total of 242 patients The Statistical Package for Social Sciences (SPSS) software version 21 was used for all data management and analysis.

Results: Of 242 patients, mean age was $39.84 \pm 4.42$. Mean disease duration was $30.00 \% \pm 4.42 .55 \%$ had connective tissue disease. 7 patients had herpes zoste infection. 4 had influenza. 5 had pneumonia, 1 had dengue fever. And 1 had herpes genitalis infection in recent 5 years.

Only 15 patients $(6.2 \%)$ had vaccination in recent 5 years. 2 female patients had inoculation of human papillomavirus (HPV) vaccine. 3 patients took shots of hepatitis $B$ virus (HBV). 2 were vaccinated for tetanus, 4 for rabies vaccine and 1 for influenza.

$159(65.7 \%)$ of the patients had heard of influenza vaccine. Only $62(25.6 \%)$ had heard of pneumococcal vaccine. $103(43.6 \%)$ of the participants knew where to take vaccine. Only 9 patients had reported of former doctors' advice to taking vaccine (influenza, 2). 144 (59.5\%) believed influenza could turn to serious infection.
$47.5 \%$ had correct knowledge of vaccination function. Only $42.1 \%$ believed vaccine was safe and valid. $8.3 \%$ of the patients thought vaccination was useless. $57.4 \%$ of the patients would like to take vaccine if medical insurance could cove vaccination. Only $37.6 \%$ of the patients preferred to take vaccine with doctors recommendation.

Conclusions: There is a need for educational intervention and awareness campaigns over the importance of vaccination in patients with rheumatic diseases.

\section{REFERENCES:}

[1] 1. van Assen S, Elkayam O, Agmon-Levin N, et al. Vaccination in adult patients with auto-immune inflammatory rheumatic diseases: a systematic literature review for the European League Against rheumatism evidencebased recommendations for vaccination in adult patients with auto-immune inflammatory rheumatic diseases. Autoimmun Rev 2011;10(6): 341e52.

[2] Papadopoulou D, Sipsas NV. Comparison of national clinical practice guidelines and recommendations on vaccination of adult patients with autoimmune rheumatic diseases. Rheumatol Int 2014;34(2):151e63.

[3] van Assen S, Agmon-Levin N, Elkayam O, et al. EULAR recommendations for vaccination in adult patients with autoimmune inflammatory rheumatic diseases. Ann Rheum Dis 2011;70(3):414e22.

[4] Singh JA, Furst DE, Bharat A, et al. 2012 update of the 2008 American College of Rheumatology recommendations for the use of disease-modifying antirheumatic drugs and biologic agents in the treatment of rheumatoid arthritis. Arthritis Care Res (Hoboken) 2012;64(5):625e39.

Acknowledgements: None.

Disclosure of Interest: Y. Jiang: None declared, X. Li: None declared, X. Zhang None declared, Q. Lv: None declared, Y. Zhang: None declared, J. Qi: None declared, Z. Liao Grant/research support from: National Natural Sciences Foundation of China [grant number 81201372], J. Gu Grant/research support from: the 5010 Subject of Sun Yat-sen University (2007023)

DOI: 10.1136/annrheumdis-2018-eular.2772

\section{AB1278 MOBILE DEVICE-AIDED HEALTH CARE: ADMINISTRATION OF NEW HEALTH CARE IN CHINA}

Q. Lv, Y. Jiang, J. Qi, Y. Zhang, X. Zhang, Z. Liao, Z. Lin, J. Gu. Rheumatology The Third Affiliated Hospital of Sun Yat-Sen University, Guangzhou, China

Background: , ${ }^{\text {Till }} 2016$ the total population of mainland China has reached 1.38 billion, while there are only 2.21 licensed/assistant physicians per thousand people. ${ }^{1}$ Another serious problem is uneven geographical distribution of medical resources. Less than $3 \%$ of general hospitals are responsible for more than $40 \%$ of medical service. Limited medical resources and distribution imbalance lead to countless of trans-provincial medical behaviours, resulting in an increase of economic cost and time cost. Meanwhile, China's mobile Internet communication is booming. By the end of 2016, there were 1.32 billion mobile phone users nationwide. $^{2}$ Based on these advantages, a new type of digital medical care has been developed rapidly in China.

Objectives: Our aim was to describe current situation of medical care and mobile medical care in China, and then to analyse medical big data to help manage chronic diseases such as rheumatic diseases.

Methods: Distribution and number of medical resources were acquired by the website of National Bureau of Statistics of the People's Republic of China and National Health and Family Planning Commission of the People's Republic of China. 7 biggest digital medical services and other healthcare websites or applications were compared in the aspects of application function, numbers and distribution of registered doctors and patients, and chronic disease management.

Results: According to different stages of medical interventions, operation modes of digital medical services can be divided into different types. Major functions encompass reservation, payment and medical consultancy. 3\% of applications involve the management of chronic diseases. Many mobile medical platforms rely on doctors from comprehensive hospitals. Patients with definitive diagnosis and initial treatment could be managed and followed-up via the platform. This Internet management mode of chronic diseases currently attracts 389407 specialists from comprehensive hospitals and 895921 patients with chronic diseases. Although the number of registered doctors in the southeastern areas is absolutely higher, many doctors are more accepting Internet-based medical practice in relatively poor western regions. The proportion of physicians and patient with chronic diseases is very large. The top 5 departments of registered users are related to chronic diseases.

Conclusions: Limited medical and health resources and distribution imbalance is a serious problem in China. A new mode of digital medical service may help manage chronic diseases. 